Aletheia

ISSN: $1853-3701$

publicaciones@fahce.unlp.edu.ar

Universidad Nacional de La Plata

Argentina

\title{
Aprendiendo en el "más acá": Entrevista realizada a Quimey Sol Ramos en el Bachillerato Popular Trans "Mocha Celis", el 25 de agosto de 2019
}

\section{Raina, Andrea}

Aprendiendo en el "más acá": Entrevista realizada a Quimey Sol Ramos en el Bachillerato Popular Trans "Mocha Celis", el 25 de agosto de 2019 Aletheia, vol. 10, núm. 19, 2019

Universidad Nacional de La Plata, Argentina DOI: https://doi.org/10.24215/18533701e029

Esta obra está bajo una Licencia Creative Commons Atribución-NoComercial-Compartirlgual 4.0 Internacional. 


\title{
Aprendiendo en el "más acá": Entrevista realizada a Quimey Sol Ramos en el Bachillerato Popular Trans "Mocha Celis", el 25 de agosto de 2019
}

\author{
Learning in "the most here": Interview with Quimey Sol Ramos at the Trans High School "Mocha Celis" on August \\ 25,2019
}

Andrea Raina

DOI: https://doi.org/10.24215/18533701e029

Facultad de Humanidades y Ciencias de la Educación, Universidad Nacional de La Plata, Argentina

andreac.raina@gmail.com

\section{Resumen:}

Dialogar con Quimey Ramos es mínimamente una invitación a preguntarnos, a repensarnos, a emocionarnos, a debatir... a cuestionarlo todo.

Entrevistarla fue una experiencia transformadora en los términos que ha enseñado Alessandro Portelli: involucrando nuestra subjetividad como historiadores/as, aumentando nuestras responsabilidades en el oficio; pero también y sobre todo, desde lo primero y más simple que es nuestra humanidad. Cada una de las reflexiones que Quimey nos compartió caló un poco más hondo, llegando al hueso de cada una de las preguntas, pero para encontrarnos con mas inquietudes; como en un juego de Mamushkas interminable que nos topaba con sentidos más profundos cada vez. Con la capacidad de entrar en un laberinto pero saliendo cada vez con más claridad, afirmando aquellas certezas con la convicción que sólo las verdades vividas te dan.

Hablamos, de memorias, de verdades, de in-justicias, de historias, de derechos, de subversión, de educación, hablamos del "más allá" y el "más acá" de una sociedad que divide, hablamos de la necesidad de reconocernos, de sincerarnos y del cambio urgente que queremos

Palabras Clave: Memoria, Verdad, Derechos humanos, Género, Educación, Identidades.

\section{Abstract:}

Dialogue with Quimey Ramos is minimally an invitation to ask ourselves, to rethink, to get excited, to debate ... to question everything.

To have done the interview with her was a transformative experience in the terms that Alessandro Portelli has taught: involving our subjectivity as historians, increasing our responsibilities in the job; but also and above all, from the first and simplest thing, which is our humanity.

Each one of the reflections that Quimey shared with us dug a little deeper, getting to the bone of each of the questions, but to find ourselves with more concerns; as in an endless Mamushkas game that ran into us with wide senses every time. With the ability to enter a maze but leaving more and more clearly, affirming those certainties with the conviction that only the lived truths give you. We talk about memories, truths, in-justices, stories, rights, subversion, education, we talk about the "beyond" and "the most here" of a society that divides, we talk about the need to recognize ourselves, to be honest and we talk about the urgent change we want.

KEYwORDS: Memory, True, Human rights, Gender, Education, Identities.

\section{Andrea: ¿Qué significa Memoria, Verdad y Justicia para vos, Quimey?}

Quimey: Hay algo sobre la verdad, en este momento de postverdades y todo eso, pero hay algo sobre la verdad, de las más genuinas... yo pienso mucho en la activista Marlene Wayar que hace un nexo sobre la memoria travesti. Marlene hace aportes valiosísimos para repensar la trayectoria de activismo travesti y de lucha travesti. Y en cuanto a la verdad entonces, Marlene habla de que no necesitamos mucho más que permitirnos esa verdad genuina de... Ella habla de esta alegoría, de la fábula del Rey: que llegan unos viajeros y le venden un traje invisible para los tontos o los ingenuos. Solamente los tontos no podían verlo, y como el Rey no lo veía, ante la vergüenza de decir que no lo veía y quedar como un tonto, se los compra. Un día sale a pasear por el reino, desnudo -y todo el mundo sabía del traje del Rey que solamente los tontos no lo veían-, 
todo el mundo celebraba el traje del Rey. Hasta que un día, un niño se ríe y dice: "el Rey está desnudo". No necesitamos mucho más para comenzar ciertas transformaciones.

Las verdades están ante los ojos de todes nosotres. Quizás hace falta recuperar un poco esa esencia de lo genuino, porque después adornamos las verdades con todos unos complejos, unos armatostes ... como unos andamios que complejizamos, en los cuales nos perdemos en los enrosques de todo lo que sabemos que tenemos que negociar, no?

Entonces los Derechos Humanos a nivel internacional dicen que los genocidios son "de aquí a acá", entonces toda la sociedad sabe que nosotras morimos jóvenes. Decir la verdad es decir: ustedes saben que morimos jóvenes. Digan la verdad, no? Bueno eso lo dice Susy Shock. Digan la verdad, digan la verdad que nos cogen a escondidas, digan la verdad que nos desean en secreto, digan la verdad: saben que jamás han compartido con nosotres la escuela, ni la familia, ni el trabajo y que nunca jamás les importó saber por qué, admitan esa verdad y háganse cargo. Y no sean culpables, pero admitan esa verdad. Y la verdad, para mí, la verdad travesti es una verdad que ... digan la verdad de que nos echan de chicas, digan la verdad de que son buenos varones progresistas, que se dejan crecer las patillas pero que después les pegan a sus hijos, o sus hijas, o que los miran firmemente con una mirada de esas que dan miedo cuando una es chica, y que lo dicen todo; porque agarraron la muñequita y no el autito o que justo pegó un gritito de alegría, entonces desde chiquititos los reprimen para cagarles la cabeza y que sean los varones violentos en los que se convierten.

Entonces la verdad travesti es una verdad que se grita con furia, que es la furia que nos deja un identicidio, que si no es milenial es centenario. Porque nosotras, digo el género es una construcción social que es indivisible, no puede ser pensada escindida de su contexto histórico. Lo que actualmente son representaciones y características de la masculinidad, en lo estético, por ejemplo, hace cien años eran los contrarios y viceversa. Por decir una pavada, porque son pavadas en comparación con otras cuestiones, los tacos eran una vestimenta masculina porque daban altura, hasta que se rescataron que eran absolutamente incómodos y se los encajaron a las pibas (risas). El color rosa era para los bebes varones de la nobleza, asignados varones mejor dicho.

Y la furia con la que se grita, es una furia del identicidio, como dice Marlene, es un genocidio en relación a nuestras identidades. Porque nosotras hemos existido desde que existe la humanidad, lo que pasa que en otro contexto nos referíamos distinto, en este contexto aparecemos como algo nuevo, porque la narración en este mundo en el que vos y yo caemos en este momento acá, parece que desde siempre fue Adán y Eva, con características corporales muy definidas. Sin embargo en América Latina, antes de la conquista europea, haciendo el mismo ejercicio que nos ha enseñado el feminismo, de encontrarnos en segundas, en terceras y hasta en cuartas relecturas de los textos oficiales, podemos dar cuenta de que los mismos conquistadores dan cuenta de nosotras en ese mundo que se encuentran. Por ejemplo, Álvar Núñez Cabeza de Vaca naufraga cerca de una isla de Panamá, y al llegar dice que los cuerpos que -esto es un relato que está en las Crónicas de Indiasdice que había una población de mujeres, ancianos, niños, niñas y "otros cuerpos que nada se diferenciaban de las mujeres salvo en su capacidad de engendrar". Y se da cuenta también que son los primeros cuerpos llevados al espacio público de esa comunidad para ser ultrajadas, asesinadas, desmembradas y desde entonces es lo necesario, también, para construir el binarismo. Digo esta construcción es parte de la herencia, de la imposición colonial.

De la misma forma, el primer Inca que es llevado para ser presentado ante la Corona Española. Se le enseña a escribir en cautiverio, y él dice que allá de donde él venía no existían los hombres, y no sabemos qué significa, si los hombres blancos, los hombres europeos, la visión de la humanidad "hombre"; o efectivamente del hombre como sujeto conformado y construido a partir de todas las características que se le han asignado e impuesto que deben portar los cuerpos con pene. Entonces, además de, como otra prueba más contundente, nuestra exigencia a pesar de la Conquista, el registro en comunidades donde ya no tenemos el mismo rol, como los Mapuches. Se sabe que en las comunidades Mapuches nosotras teníamos... las trans y travestis, no hay relatos de las masculinidades trans -quizá también porque aún hoy el grado de invisibilidad de las masculinidades 
trans es altísimo- habría que ver por qué... Pero bueno las femineidades trans tenían un lugar social muy importante, eran consideradas como chamanas, consejeras, no sé el nombre, pero tenían un rol importante.

En fin historias hay un montón, sin embargo no es gracias a ningún poder instituido hasta ahora, y no es gracias a ninguna inclusión, digo nosotras existimos porque seguimos naciendo. $Y$ ahí hay algo muy importante a entender, como dice Judith Butler, que existen ciertas normas sociales que posibilitan la vida, en los casos en que esas normas son tan tajantes lo que nos lleva es a la no existencia. Y por eso un promedio de vida de 25 años, nosotras seguimos existiendo a pesar del binarismo, a pesar del patriarcado, a pesar del capitalismo, a pesar de las patrias... Digo, no? seguimos existiendo por nosotras mismas, porque efectivamente la humanidad no puede ser limitada a varón y mujer, no puede ser limitada a eso. Existimos siempre.

Digo lo que sí creo que es nuevo, en nuestra sociedad actual, es que se están reconfigurando los roles y las identidades por lo que surgen posibilidades de pensar de un abordaje nuevo desde las viejas estructuras que tenemos, un abordaje distinto sobre las identidades de género en sí. Pero eso no significa que no hayamos existido siempre. Y que hombre y mujer son imposiciones.

Andrea: Entonces volviendo un poco a memoria, verdad y justicia con todos estos sentidos que me decís...

Quimey: Bueno en derecho internacional parece que no aplicamos a Genocidio nosotras, porque para ser considerado Genocidio el grupo tiene que compartir características culturales similares. Pero se ve como el sexo/género no es cultural, no entra. Y sin embargo hay algo que más allá que las travestis seamos gitanas, judías, católicas, de origen, no? compartimos un destino común, que es el ser empujadas al borde del borde social. Ser estigmatizadas por todos los grupos sociales y ser condenadas a una muerte temprana.

Yo pienso eso, que Verdad sería empezar por reconocer, todas las veces que hemos sido cómplices de esto. Y sin dejar de decir que cada quien tiene distintas responsabilidades. Porque la persecución policial ha cambiado en este momento, antes era absolutamente total para todas las trans y travestis, ahora para un 95\%; habemus un 5\% que no somos perseguidas digo, hay un cambio no? Pero cómo puede ser, a mi me queda grabado cuando Susana Roussi, mamá de Gonzalo -un pibe trans de La Plata-, le escribe una carta a Gonzalo y dice: cuando yo me enteré que iba a ser mamá de una nena, cuando estaba embarazada pensé cómo había sido mi mamá conmigo, todos los aspectos que me habían gustado de mi crianza, los que no, repensé mi infancia y mi mamá. A partir de ese imaginario, a partir de esas representaciones hice lo que pude. Cuando me enteré que en realidad era mamá de un pibe trans, me puse a pensar qué sabía de las personas trans, y en qué otras situaciones de mi vida había compartido con personas trans; y ahí me angustié, dice, porque entendí que nunca había tenido personas trans en mi familia, que jamás había compartido trabajo con una persona trans, que jamás había estudiado ni en la escuela ni en la universidad con una persona trans, que no me las había encontrado haciendo trámites, que no las tenía en mis rondas de amigos, no compartí un domingo de asado; la única imagen que yo tenía de las personas trans eran las chicas que veía paradas en la esquina cuando pasaba rápido con mi auto, no?

Andrea: Es clarísimo...

Quimey: Es clarísimo, y además funciona en ese sentido como Gueto: si hay una parte de la población que no es libre de transitar por gran parte de la ciudad y está confinada a sociabilizar en determinada zona, es realmente alevoso y sucede ante los ojos de todos. Y lo que hay que entender, digo bueno, yo no quiero comparar en el sentido de si era igual, mejor, peor. Pero digo hay relación porque los campos de concentración estaban a la vista de las comunidades cercanas, digo la gente era consciente que existían personas encerradas. Lo mismo pasa con las cárceles pero bueno ahí hay toda una justificación del Estado Moderno, como si no supiéramos que de repente adentro de las cárceles tenemos el doble de la población para la que están preparadas, que hay un porcentaje que no sabemos pero que es altísimo de personas que están indocumentadas ahí adentro. Que no hay constancia que están allí, salvo porque han dicho mi DNI es tal, por lo demás son NN. Esas personas son las que las mafias utilizan para sacar de las cárceles y hacer sus trabajos peores, y si les pasa algo afuera, nadie va a reclamar por ellas. Y eso pasa delante de todos nosotros, en este mismo territorio. Entonces, y ahí también hay travestis y sobre todo migrantes. Porque en los pabellones hay 
trans y travestis, que ahora les pusieron "pabellones de la diversidad", y es una burla. Porque esos pabellones antes eran de homosexuales, y antes de los desviados. Físicamente sigue siendo el mismo espacio, y los cuerpos que están ahí adentro también, las compañeras comparten con sátiros el pabellón.

Sabes ¿̨por qué digo todo esto? Es por la misma razón, por la que Diana Sacayán se nombraba activista de los derechos humanos. Porque sino esto parece una mera cuestión de los grupos "antiderechos" y de los más rancios que nos han perseguido siempre, se justifican con esto de decir que somos una "novedad", que son nuevas configuraciones. Mezclan todo y parece que se trata de una libertad democrática que nos dan derecho a existir o no. Cuando en realidad nuestro derecho a existir no se puede arrebatar, es. No me sale la expresión jurídica propiamente, y es previo, por eso una reclama la autopercepción, porque es preexistente. Ustedes hagan todo lo que quieran pero yo no voy a negociar mi identidad, yo ya existo efectivamente, estoy acá de carne y hueso; mi existencia no se negocia, tener que negociarla es lo que nos lleva al borde de la muerte, entendés?

Entonces, no se trata de libertades democráticas se trata de derechos humanos, un derecho a ser. También como decía Marlene- hay algo de la existencia travesti asociada, o por estar asociada al mundo de lo sexual, y la identificación de lo sexual con el campo de las libertades, donde se cree que nosotras somos sujetas extasiadas que vivimos en el margen de lo más libertino. Y Marlene, esto es bastante polémico pero en el 2003 decía, en un debate sobre la prostitución o trabajo sexual decía más o menos: se pretende dejar fuera de este debate el término de redes de trata porque no fuimos arriadas por la fuerza para ser prostituidas, como si no hubiésemos sido subjetivadas para llegar hasta acá. Porque en tal caso, dándolo vuelta la víctima de una red de trata tiene un momento bisagra, de inflexión de pérdida de libertad y puede albergar la esperanza de recuperarla. Hay un momento contundente donde se pierden muchas libertades. Nosotras tenemos que desandar el haber sido subjetivadas de esta manera, tenemos que deshacernos del constructo social inserto en nosotras para darnos cuenta que podemos hacer otras cosas. Las contraposiciones a veces son problemáticas, no? Por eso me parece que no está bien dado el debate entre regulacionismo y prostitución, porque esas son posturas -como también dice Marlene- son posturas jurídicas, hablando en un plano de derechos, mirando y señalando el Estado. Pero después las sujetas más allá de las definiciones, atraviesan las mismas situaciones, no? Están en lo mismo. Y de la misma forma esta contraposición de pensar red de trata, o libertades no quiero que nuble una cuestión de profundidad, que para nada sirve contraponer cómo es la subjetividad de una persona que está secuestrada en una red de trata con alguien que desde muy chiquitita se construye pensando que no vale una mierda. Pero lo que es importante que se entienda, que es muy complejo cómo todas funcionamos orgánicamente, para que solamente subsistan y accedan a una alegría -que también es una construcción- los cuerpos que pueden acceder a eso.

Yo no voy a dejar de decir que el amor romántico y monogámico es una mierda, pero no pudimos acceder ni a eso. Nuestro rol es el deseo secreto, el deseo tabú, el deseo reprimido. No somos merecedoras de amor. Y nosotras nos hemos construido con esas representaciones de nosotras mismas, no somos merecedoras de amor.

Andrea: Escuchándote se me venía que justamente somos "el resto", los que tenemos que aprender y desandar; deconstruir y hay mucho que aprender para que todes podamos vernos de otra manera... Pensaba los límites también de los derechos, aunque los derechos humanos te dan la base, no? la existencia... aunque sean la base pero después todo esto que vos estás diciendo es cultura, es historia, subjetividades... ¿cómo hacemos en este presente?

Quimey: Esto me lleva a un punto neurálgico que es: que mi activismo no pasa por atender o repensar la existencia trans sin constantemente hacerla dialogar con la existencia del binarismo hombre/mujer; porque si no, es caer en una trampa del heterocispatriarcado. Porque nuevamente se descontextualiza, el contexto es: nosotras somos trans, que trans es "lo de más allá", específicamente viene de ahí ese término, porque hay "un más acá", una pertenencia y nosotras no tenemos esa pertenencia, estamos en un "no lugar". Ahora qué hay para aprender de ese "no lugar". Porque todas estamos ungidas de tener un espacio. Y muchas veces por 
eso es, creo yo, que se generan comunidades de trans y travestis, que funcionan además, se nombran como familia: alquilan una misma casa, hay una madre, la más vieja le dicen la abuela, están las hijas, no? Eso es una posibilidad y es una experiencia muy interesante de pensar en contextos de supervivencia y en contexto de las representaciones que las compañeras han tenido.

Pero después nosotras, también, luchamos para construir otras representaciones; y ahí aparece la Mocha, una representación de comunidad, que dialoga con las estructuras familiares, pero que a su vez -digo porque a más de una se le escapa un "papá" hablándole a algún profe- es distinto, somos muches, es otra cuestión y suceden cosas maravillosas dentro del dolor. Por ejemplo, este año falleció una estudiante de la escuela, cosa que pasa todos los años. Todos los años hay al menos dos compañeres que mueren... El mismo día que nos enteramos, que era un lunes, yo hablo con el curso y les pregunté; porque en cualquier otra institución se decretaría el duelo; entonces acá preguntamos, ¿y por qué? Porque en cualquier otra escuela, hay duelo porque cuando te vas de la escuela en teoría vas a volver a un núcleo familiar, y si estás afectada por la situación va a haber una contención por fuera. Acá muchas veces no está esa contención si no es acá. Entonces hablamos explícitamente de esto, y fue una decisión colectiva si hacer duelo o no. Y eligieron sostener las clases.

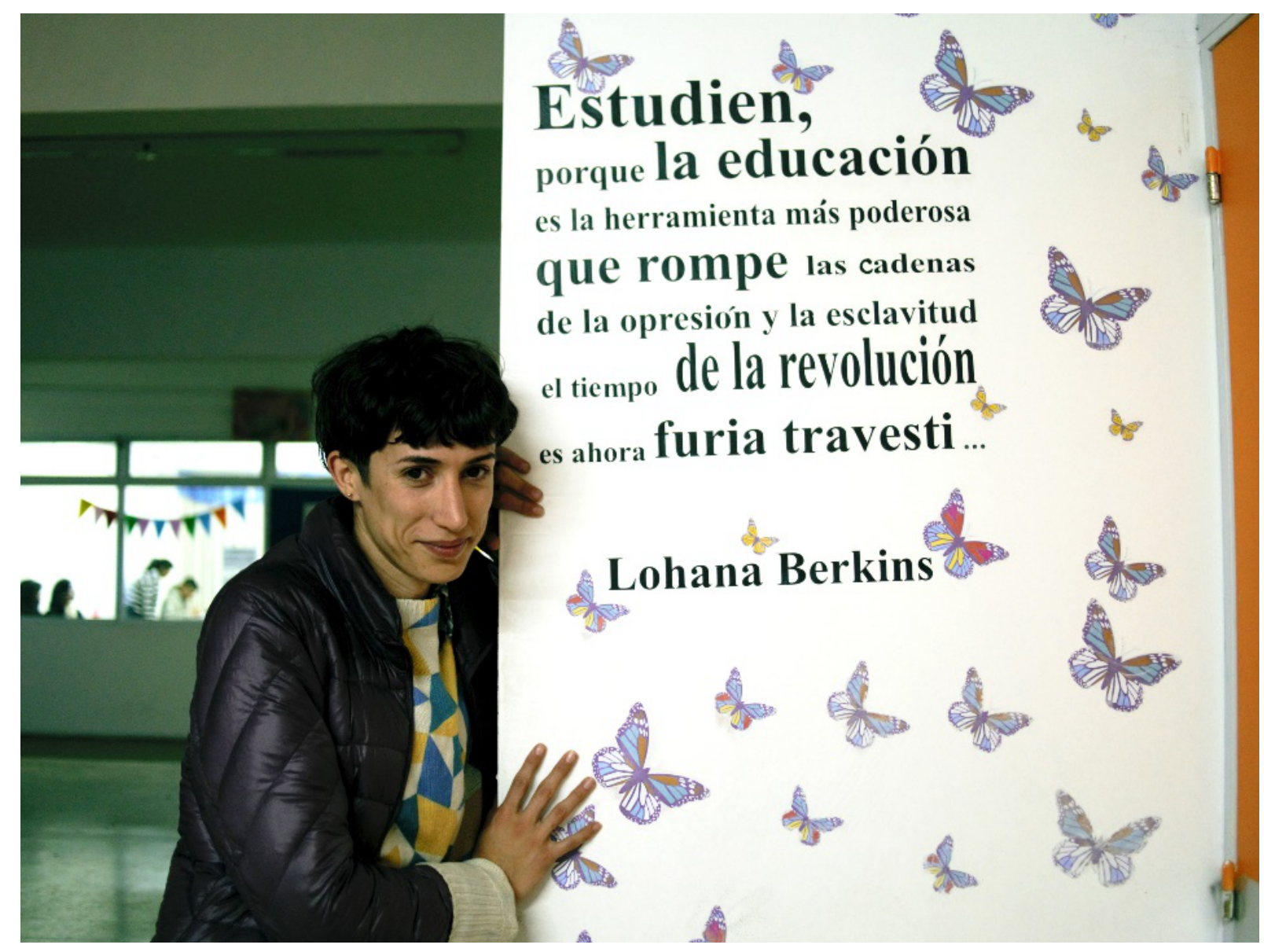

Andrea: Sin duda la contención está acá adentro... Justo de lo que estabas hablando, la pregunta que se me vino ahora: ¿Cómo te parece que se pueden dar estos diálogos -que creo totalmente necesarios- con este "más acá" que nos representa a este resto? Digo si queremos generar un cambio...

Quimey: Yo adopto una postura muy crítica, entonces, digo, les exijo a todes: Digamos la verdad. Y consecuentemente construyamos otra memoria, otros relatos de nosotres mismes, porque por ejemplo mi mamá -a mi me quedó grabado que contó de su infancia- siempre jugó con los varones, y a los diez años de repente le crecieron las tetas y se las escondía debajo, se ponía muchos buzos, se las tapaba y le quedo esta postura [hace un gesto con los hombros hacia adelante y el pecho hacia atrás] que claramente tienen 
muchas masculinidades trans y muchas tortas; porque no quería tener tetas, porque tener tetas significaba no poder jugar más con los varones que era lo que le gustaba, porque los juegos que eran "para varones" le gustaba: treparse a los árboles, tirar con la gomera, no? Porque además, de repente pasas a ser un objeto de deseo, donde todas las guarradas están habilitadas. Entonces al principio cuando ella me lo contaba, yo me preguntaba: ¿será que mi mamá es trans y no sabe? Actualmente no me cabe ninguna duda, digo bienvenida el día de mañana si quiere ser trans; pero no es así como ella se piensa. Ella es una mujer cis heterosexual que simplemente al igual que todes ha padecido al binarismo profundamente, y ha padecido la imposición del género que le tocó profundamente. Entonces todes -y esa es la cuestión- asumir que todes hemos padecido debido a nuestro género. Algunes más otres menos, algunes han sabido negociar más, otres menos. Algunes se han adaptado mejor, pero todes hemos padecido; entonces ¿por qué seguir repitiendo ese padecimiento?

Y también desandar los mitos: porque muchas veces la empatía con nosotres muchas veces es por imaginarse "lo que debe ser el sufrimiento de encontrarse en un cuerpo que no te corresponde, en un cuerpo equivocado" Ideas más alienantes imposible! no? Porque yo no sé vos, mi cuerpo no está equivocado, por empezar porque es indivisible mi existencia de este cuerpo- Yo desde que existo soy este cuerpo, yo soy con este cuerpo. Entonces eso es anular absolutamente nuestras potencias políticas, afectivas, deseantes. Y a su vez es negar la incorfomidad con el cuerpo, propia de la humanidad. Porque no hay sujeto que no padezca en relación al cuerpo. Se nos asigna a nosotras la incorfomidad con el cuerpo y es un error. Porque la incorfomidad es dentro de un sistema que nos ha dicho "no sos posible", "no sos posible"y una así se construye. Entonces como "no sos posible", no lo sos en la escuela, y de ahí en adelante, no sos posible en la universidad, no sos posible en tu familia, no sos posible.

Con los fantasmas de cada quien y las posibilidades de cada quien, porque hay quienes en la "no existencia" han construido lugares de resistencia; porque si hay poder hay resistencia. Digo hay compañeras que se han legitimado y validado en espacios que una no creería. De hecho el fantasma de que esto es una cuestión cosmopolita y que en los pueblos no, es una gran mentira porque hay compañeras casadas por Iglesia, viviendo en Santiago del Estero. Entonces ese mito, de que somos todos "progres" porque estamos en la ciudad es una mentira.

El acompañamiento al colectivo trans no puede ser desde un lugar caritativo. Tiene que ser reconociendo cómo me atraviesa y me interpela la existencia trans y cómo pone en crisis todas mis verdades. Porque nosotras atravesamos sistemáticamente tener que estar dando respuesta a la pregunta de ¿por qué soy? "Yo soy porque desde los cinco años, desde muy chiquitita... Yo soy porque en realidad desde el embarazo era y se me cruzó un cromosoma a último momento, y qué se yo... Yo soy porque... no se, $x$ fundamentación no?" Pero nosotras tenemos que estar explicando todo el tiempo ¿Por qué somos?

Vos, alguna vez tuviste que dar respuesta a la pregunta ¿por qué sos mujer?

Andrea: No.

Quimey: Y en general no. Porque esa es la gran diferencia entre lo cis y lo trans, que algunas ya están validadas de existencia y nosotras tenemos que estar fundamentando. Y ahí sí hay conceptos más nuevos, que son parciales y nos sirven parcialmente. La autopercepción es un término que en este momento nos sirve, pero tiene un límite. Porque reivindicar que es una determinación propia está muy bien, pero de repente parece que hay gente que se autopercibe y hay gente que "es" efectivamente. Y en realidad nosotras tenemos que decir que nos autopercibimos porque lo que está implícito ahí es que primero fuimos negadas. Entonces tengo que desarrollar una respuesta.

Entonces yo creo que es eso, hay que permitir interpelarse. Y ahí hay muchas preguntas...

Lo trans, mirá yo activo desde lo Trans porque creo que es absolutamente subversivo. Y sin embargo no pienso que en cualquier contexto del mundo, en cualquier época, digo nosotras podemos perder nuestro potencial de subversivo. En Argentina estamos a la vanguardia porque hubo un movimiento político propio del colectivo trans/travesti pero ahora coincide con que internacionalmente hay una apertura a las identidades trans, Pero es una asimilación que el mercado, que el sistema capitalista prefiere hacer en este 
momento, para desactivar la potencia que tenemos de cuestionarlo todo. Lo trans es un lugar más desde donde cuestionar todo. Pero por eso es que hay que tomar con pinzas, y no cualquier visibilidad es buena.

Actualmente las tecnologías de género han avanzado a tal punto que lo que las personas trans podemos tener hoy es: "closet". Una de las diferencias entre los gays y las lesbianas y nosotras: es el closet. El closet en el sentido de poder vivir tu sexualidad en el ámbito de lo privado.

Te hablé de autopercepción, no? Orientación sexual también es un concepto que el movimiento utilizó en un momento. Porque al hablar de orientación sexual se reducía la sexualidad a un aspecto de la persona que no hacía a la identidad precisamente y que se podía vivir de forma privada. Entonces bueno: yo soy gay, soy un hombre que me acuesto con otros hombres, pero me acuesto en mi casa, en lo oscurito donde nadie me ve, no se preocupen, no se me va a caer ni una pluma. Las personas trans históricamente no tuvimos closet, porque a partir de asumirnos socialmente ya salir a la calle es manifestar, no hay closet. Es portar tu disidencia ante la norma.

A partir de estas nuevas tecnologías, la identidad trans puede pasar a ser un aspecto privado de las personas. Y pierde su potencial en ese sentido, o se desactiva mediante otros discursos, por ejemplo estos: "yo soy un cuerpo equivocado, al que le sobran o le faltan partes, necesito una sustitución, un suministro, algo que me complemente esta falla: hormonas, intervenciones". Y no está mal intervenirse u hormonarse, pero no podemos dejar de denunciar que nos están empujando para que nuestro deseo pase por ahí. Porque si no me puedo enamorar de una persona con tetas y con barba, probablemente no haya una sujeta que se pueda desarrollar felizmente, libremente, socialmente en afectos libres y alegres con tetas y con barba. Que se pueda mirar al espejo y decir: que linda estoy hoy, que ganas tengo de vivir.

Entonces yo creo que en este contexto somos subversivas porque socavamos las bases de esta humanidad que está en crisis y que lo que se niegan a decir sistemáticamente es que han fracasado. Asumamos el fracaso. Como dicen también Susy y Marlene. Asumamos el fracaso porque sino seguimos emparchando, instituciones que nos condenan al desamor, al odio. Y construyamos desde las ruinas.

Andrea: Ahora, hablando de la subversión y el peligro de la integración... "construyamos desde las ruinas", la pregunta sería: ¿Cómo hacer para el reconocimiento de los derechos? Digo ¿Cómo jugar dentro de esa subversión para no terminar siendo excluidas?

Quimey: Hay que asumir el fracaso, porque probar siempre por la misma vía es cuanto menos ser necio. Marlene hace una lectura de la prostitución muy interesante, que dice, que en su caso la prostitución le permitió aprender a negociar, no? Y en esa negociación no podemos seguir haciendo siempre la mayor cantidad de cosas posibles por la menor remuneración. No podemos seguir mendigando. Ella dice, aquella que pasó por la prostitución sabe que primero se cobra. Y ella me decía, ¿qué trabajador conoces vos que cobre por adelantado? Entonces, para mí no podemos dejar en tal caso tampoco de..., digo hay que aprender a negociar. Y a su vez yo lo que le agrego, la parte que le discutía a ella, no podemos dejar de enunciar y de denunciar que se nos impone la negociación: como forma de vinculación capitalista. Se nos impone la negociación, pero yo no quiero negociar más. Yo quiero potenciarme.

Porque además, sobre todo, la negociación siempre la hacemos en desventaja. Jamás vamos a llegar a buen puerto negociando, porque en tal caso se disfraza de negociación algo que termina siendo una imposición también. Entonces tenemos que tejer trincheras afectivas, políticas, deseantes, colectivas para cambiar esa balanza. Nosotras tenemos que construir comunidad.

Y ahí, por ejemplo en la escuela cobra un rol central la Educación Sexual Integral. Porque -como dice Val Flores- la escuela se ha consolidado necesariamente dejando por fuera a las pasiones, a los deseos y a los afectos. La construcción de conocimiento no puede permitir mezclarse desde la lógica positivista, hasta hoy en día, con los sentimientos, con el campo de lo sentimental; porque eso amenazaría la validez de la verdad de ese conocimiento. Como si los sujetos que construyeron esos conocimientos no hubieran estado atravesados por deseos, afectos y pasiones. Entonces es permitirnos ponernos en duda todo. Sí creo, que hay un par de 
caminos de los cuales aprender para permitirnos que ese "poner en crisis todo" no sea tan desolador. Esto, hay que construir comunidad.

Yo no me puedo preguntar a mi misma como me preguntaba la Inquisición. No me puedo preguntar a mi misma como me preguntaba el policía contra la pared para ver si tenía el DNI o no, no. Yo me tengo que poder preguntar abrazándome, dándome el tiempo que me han negado. Tengo que poder preguntarme, admitiendo que mis respuestas van a ser parciales, y que tengo que habilitar sobre todo la escucha para encontrar otras respuestas de otres, que a mí me puedan potenciar. Por ahí la primera respuesta es que no puede hacerse en la soledad, y no puede hacerse si no es sistemáticamente desactivando la lógica de la falta, de la culpa y de la pena que nos han impuesto. La pena en un sentido punitivo, no? Nos preguntamos de forma punitiva, entonces no puedo admitir que fui abusada porque si admito que fui abusada lo siguiente que sigue es ¿por qué no pude evitarlo en ese momento? Y me castigo con eso: ¿Por qué no pude? Y no pude, no pude, no pude decir que no, en ese momento. Y no tengo culpa sobre eso. Pero ahora soy consciente.

Yo creo que es esto, es un paradigma de la búsqueda de autonomía.

Hay cosas que tenemos que trabajar a futuro. Pero también podemos trabajar desde el paradigma de la reparación. Nosotras construimos escuela en la urgencia, y desde la urgencia. Es una urgencia acceder a la escuela para este colectivo porque lo han negado sistemáticamente, lo hacemos en situación de urgencia permanente. Y reconocer que este es nuestro campo, que nosotras queremos estar allá y proyectamos allá, a la distancia y tenemos la capacidad de verbalizar a dónde queremos ir; pero hoy estamos acá porque la urgencia es lo que permanentemente emerge. La urgencia de: me están desalojando, me quedé sin trabajo, y hacemos escuela en este contexto. Para mí, es desde un paradigma de la reparación porque estamos en un Bachillerato de adultes: La Moccha. Entonces tenemos que partir desde esta posición, la escuela es un derecho fundamental de la infancia y la adolescencia. Si estamos en un Bachillerato de adultes tenemos que mínimamente tener una perspectiva crítica del Estado, porque se trata de que el Estado en su rol de garante de derechos ha fallado. Y todas las personas que llegan acá, porque en su debido tiempo según los estándares legales, no han podido. El Estado ha fallado. Y nosotres acá estamos reparando. Y desde esta lógica de la reparación, intentar de reparar la forma de construir vínculos. Proponer otra forma de construir vínculos.

Andrea: Un montón de trabajo. Pensaba esto, ¿cómo construir estas comunidades? ¿qué hacemos? En este contexto, se supone más propicio para la defensa de derechos que deberían ser inalienables. Hay algo de tu disposición -desde vos, desde todo lo que te constituye- al diálogo, que ya te dije, que hizo más viable esta posibilidad. Pero no resulta tan simple con otres, a lo mejor también es una cuestión generacional...

Quimey: Me voy a poner un poco filosófica, yo soy una persona absolutamente invadida de emociones. Paso desde situaciones en las que me emociono, de una angustia profunda y de repente encuentro una esperanza, un refugio chiquitito donde digo algo estamos haciendo, pero quizás es entendernos, hay que salirse... me voy a volver re abstracta de nuevo.

Insertas en una lógica muy cristiana, que impregna todos los movimientos sociales, y todas las estructuras de hoy en día; estamos buscando el paraíso al final de esta vida martirizada, donde nos preocupamos todo el tiempo de no errar. Nos desvivimos por ese paraíso y por consagrarnos. Puede ser a título personal o del movimiento obrero, no? Por decir un ejemplo. Somos parciales, somos así de chiquitas en contexto, tenemos límites, tenemos muchísimos límites. Yo hago la experiencia, porque soy joven, de empujarlos y volverlos laxos, cual músculo, lo más posible, pero sé que tenemos límites. Yhay que aprender a pensar, entonces, lo que nos trasciende no como esa búsqueda de eternidad, sino como lo finitas que somos, saber que nuestra vida en la historia de la humanidad, somos muy chiquitas y hay que animarse a pensar que estamos construyendo otras posibilidades para otres. En este presente, no en futuro.

A mí me angustia mucho ver el sufrimiento de compañeras más grandes, porque una se ve identificada y pienso en sus propios sufrimientos íntimos, que por ahí los tenes desde muy chiquita, y esto me va a acompañar toda la vida. Pero las cosas a las que yo le estoy dando vueltas, ya no son las mismas que las que le daban mis compañeras de hace 20 o 30 años. Hay un hilo ahí, donde no es en vano nuestra resistencia. 
Y animarse a ceder para no caer en otro fracaso. Que con tal de consagrar al movimiento, me enquisto yo como un grano en el orto de toda esta comunidad durante 20 o 30 años. No puedo estar en constante diálogo con quienes vienen. $\mathrm{Y}$ animarnos a corrernos. $\mathrm{Y}$ a reclamar a los candidatos y todo. Decirles che, van tres elecciones que sos el mismo candidato, y yo te admiro un montón, pero no podes ser mas vos. Porque te seguimos mirando a vos como que seas el gran salvador, y por más que seas re contra bueno, no sos Moisés, ya se murió hace miles de años, eso ya está, ya es fracaso entendes? Te crees tan omnipotente que si no sos vos, no va a aparecer ningún otro cuadro que tenga la capacidad de conducción. Deja que la juventud se desarrolle, que se vuelvan sujetas de creación activa sobre su realidad. Y, a parte, el sistema es tan perverso que hacemos "un adentro" tan sesgado de "ese afuera", tan delimitado que si no soy yo, no es nadie. Animarse a ceder, que la historia continúe, entenderse una como hija de su historia y no tan omnipotente.

Yo entiendo que lo que planteo, lo hago desde un lugar discursivo potente, lo hago con una convicción pregonera en algún punto, y que hay mucho recorrido hasta acá. Porque activo desde muy piba y, desde muy piba pongo el ojo y mis sentidos en les otres también. Sé que al principio nos obligan a todo lo contrario, a achicarnos lo más posible. Tus dos o tres amigos de secundario, tu familia, tu marido, tu esposa y hasta ahí. Bueno, pero hay que sacudir eso.

Hay que sacudir ese núcleo de lo seguro. Y hay que aceptar la incertidumbre de lo que se viene, con responsabilidad. O sea yo no soy economista, voy a buscar la compañera que desde mi sentipensar se acerque a lo que yo creo que va a poder construir profesionalmente, con herramientas a la cual ha dedicado tiempo de su vida. Lo mismo con la médica/médico, y a mí, les voy a pedir que me reconozcan porque yo tengo un tránsito, entre otras cosas, como docente. Entonces reconoceme, reconoceme, no me vengas a correr. Y ahí sí construir, tomando las herramientas que socialmente necesitamos, reconociéndole a cada quien su recorrido y aceptando esos errores, no desde un lugar macrista. Porque no somos ellos y también tener esa convicción. No somos ellos, porque ellos desde que han nacido se han formado para esto, y nosotras desde que nacimos nos han hecho creer que podemos llegar "hasta ahí" y no es cierto. No es cierto. Porque a mí me arrebataron el tiempo de estudiar las tres carreras que yo quisiera estudiar. Y a todas nos arrebataron el tiempo. Eso es el capitalismo inserto en nosotras. Lugar donde miremos, pasito que demos estamos negociando. $Y$ en general el costo está sobre nuestros cuerpos, sobre nuestra vida.

Andrea: Antes de ir cerrando, me gustaría que cuentes si queres, la historia de tu bisabuela.

Quimey: Mi bisabuela Memé Hipatia Pineau de Bur, ella se nombraba Hipatia Bur en ese momento porque era el apellido de mi bisabuelo, fue también maestra rural. Desde mi bisabuela hasta mí, somos cuatro generaciones de docentes. Yo caí en cuenta este año, distintos tipos de docentes no?.Y mi bisabuela, al igual que la gran mayoría de las Madres y las Abuelas [de Plaza de Mayo] era una mujer que no tenía implicación política; no consideraba que ése fuera su lugar porque no era el lugar de las mujeres en esa época, desde el discurso hegemónico. Sí, mi tatarabuela era una 'pregonera' socialista que entiendo se fue- y eso fue un dolor para mi bisabuela- cuando ella era muy chiquita, por las provincias a hacer política. Y ella quedó criándose con unas tías, porque el padre tampoco se hizo cargo. Entonces entiendo que no tenía un interés por la política hasta que la necesidad y urgencia -que es lo que en general nos enmarca- la hizo tener que salir, porque habían desaparecido a su hijo y a su nuera. Y bueno eso, yo sé muy poquito de ella.

Andrea: ¿Del hijo de ella: que era tío abuelo tuyo, sabes algo más?

Quimey: Raúl Bur, que vivía en Mar del Plata, que estaba casado con Alicia...Habían militado en el PCML (Partido Comunista Marxista Leninista).

Andrea: Ahora sí para ir terminando, hemos hablado de todo... ¿ con qué te gustaría cerrar?

Quimey: Esto: para mí, el lugar crucial de la ESI (Educación Sexual Integral) es que tiene un lineamiento que es valorar la afectividad.

Entonces hace diez años aproximadamente, en el 2006, al mismo tiempo que se terminaba en la mayoría del país -no en todas las provincias- los edictos policiales contra las trans y travestis, digo porque por eso las compañeras dicen que la democracia para nosotras no llegó; yo podría decir que en su gran parte no llegó 
porque aún no estamos en cantidad significativa, construyendo política desde quienes nos gobiernan. Si no podemos ser nosotras electas, no hay democracia para nosotras aún. Pero además de eso, digo bueno, al mismo tiempo que se terminaban los edictos policiales, se consagraba la ley de Educación Sexual Integral y entraba una bomba.

Porque de repente irrumpe la afectividad como conocimiento en el aula. Es una herramienta que nosotras tenemos para empezar a proponer todo esto. Porque todo esto que estuvimos hablando parecería no tener fundamento para entrar a la escuela. Entonces desde los afectos, todo es válido. Todo lo que construimos no puede estar escindido de un cuerpo, de un tiempo, de una forma de sentir que se construye. Porque nuevamente lo mismo, ¿por qué sienten amor por sus esposas? No se, vamos a hablar de los tipos, y ese amor conlleva este tipo de prácticas. Y por nosotras sienten ese ardor que los lleva a buscarnos así, en el bosque con el auto, pero jamás serían capaces de construir con nosotras lo que designaron como amor para ellas: ¿por qué? Bueno pongámoslo en crisis.

Ahí tenemos una gran trinchera, en la Educación Sexual Integral.

\section{BY-NC-SA}

